\title{
Perception of the Real World- Understanding Historic Environments, an Informal Design Studio: Walking Istanbul Series
}

\author{
Çiğdem Polatoğlu1, Sadiye Müjdem Vural1,2 \\ ${ }^{1}$ Department of Architecture, Faculty of Architecture, Yildiz Technical University, Istanbul, Turkey \\ ${ }^{2}$ Department of Architecture, Faculty of Architecture, Eastern Mediterranean University, Famagusta, North \\ Cyprus \\ Email: smujdem@gmail.com
}

Received 21 January 2014; revised 21 February 2014; accepted 28 February 2014

Copyright (C) 2014 by authors and Scientific Research Publishing Inc.

This work is licensed under the Creative Commons Attribution International License (CC BY). http://creativecommons.org/licenses/by/4.0/

(c) (i) Open Access

\begin{abstract}
Design education is the most important part of architectural education. Formal architectural education (training), followed by an architect in the candidate's training period, is a whole consisting of theoretical and practical courses. In spite of this programme package, in design education, student acquires to experience the design by his/her own and this is the only way to learn how to design. In this context, aside from formal architectural education informal studies such as workshops, seminars, conferences, exhibitions, competitions, excavation, etc. have an undeniable importance. In design education, "informal studies" have some outstanding results on developing design thinking skills, learning by doing, creating motivation, intuitive knowledge and self-confidence and at the same time these studies are a suitable tool for the LLP-lifelong learning programme. In this paper, as an informal study example two workshops will be discussed to evaluate the contributions of such informal studies on student's individual and collective learning styles, design thinking techniques and practices.
\end{abstract}

\section{Keywords}

Design Education in Architecture, Informal Study, Freehand Drawing

\section{Introduction}

Architects, committed themselves to the principles of profession, honesty and competence, design built envi-

How to cite this paper: Polatoğlu, Ç., \& Vural, S. M. (2014). Perception of the Real World-Understanding Historic Environments, an Informal Design Studio: Walking Istanbul Series. Creative Education, 5, 457-469.

http://dx.doi.org/10.4236/ce.2014.57055 
ronment using their knowledge and skills. Architectural education should contribute to the development of society in social, cultural and economics both in national and international levels. In this context, architectural education programmes are reshaped involving the changes and transformation in social, political, economical and technological issues. Creating an architect profile that is responding to the social dynamics, human-centered design and highlighting architect's role and responsibilities in this new social order is becoming important.

The UIA (Union of International Architects), together with UNESCO, created and promotes the UNESCOUIA Charter on Architectural Education. This fundamental document sets directives on architectural education. Item no.5 describes that architectural education involves the acquisition of the following capabilities

(http://www.uia-architectes.org/image/PDF/CHARTES/CHART_ANG.pdf).

ITEM 5.A. DESIGN:

- Ability to engage imagination, think creatively, innovate and provide design leadership.

- Ability to gather information, define problems, apply analyses and critical judgment and formulate strategies for action.

- Ability to think three-dimensionally in the exploration of design.

- Ability to reconcile divergent factors, integrate knowledge and apply skills in the creation of a design solution. ITEM 5.B. KNOWLEDGE:

Understanding the role of architect in cultural and artistic studies, social studies, environmental studies, technical studies.

ITEM 5.C. SKILL:

- Ability to act and to communicate ideas through collaboration, speaking, numeracy, making capabilities to explore, develop, define and communicate a design proposal.

- Understanding of systems of evaluation, that use manual and/or electronic means for performance assessments of built environments.

Design education is the most important part of architectural education. Formal architectural education (training), followed by an architect in the candidate's training period, is a whole consisting of theoretical and practical courses. In spite of this programme package, in design education, the student acquires to experience the design by his/her own and this is the only way to learn how to design. In this respect, it is possible to talk about three stages in architectural education.

First stage is gaining knowledge and skill for establishing fundamental knowledge; second stage is using the gained knowledge and skills and the third stage is focused on producing/developing new knowledge from the gained ones. As shown in Table 1, YTU Department of Architecture determined its programme outputs (in the context of set criteria of National Architectural Accreditation Board-MIAK) according to these three stages.

These criteria are also determine the knowledge and skills in design such as, critical thinking skills, graphical presentation skills, research skills, formal composition systems, design skills, teamwork skills, use of precedents, human behaviours, cultural diversities, accessibility, sustainable design, ability to prepare a comprehensive program, site conditions, building systems integration, the role of client (user) in architecture, and comprehensive design.

The studio in design education is the place where all above criteria come together. From this point of view studio can be defined as (Polatoğlu \& Canbay Türkyılmaz, 2009):

- a place where all the knowledge is integrated,

- a discussion platform where various relations are developed,

- a communicative organization between receiver and sender.

In this context, aside from formal architectural education informal studies such as workshops, seminars, conferences, exhibitions, competitions, excavation, etc. have an undeniable importance such as (Polatoğlu, 2011):

- Developing design thinking skills,

- Learning by doing,

- Creating motivation, intuitive knowledge and self-confidence and at the same time these studies are a suitable tool for the LLP-lifelong learning programme.

In general the scope and objectives of the informal workshops can be summarized as:

- to solve a design problem in a short-time period,

- to promote group work,

- to bring together different cultural and architectural environments,

- to give wider point of views,

- to improve oral and written communication techniques, 
Table 1. Student performance criteria of MIAK (derived from NAAB that YTU Architectural Department follows) and the Modules of Architectural Education in YTU (Ünver, Polatoğlu, \& Vural, 2013).

\begin{tabular}{|c|c|c|}
\hline 1st MODULE/1st and 2nd years & 2nd MODULE/2nd and 3rd years & 3rd MODULE/4th years \\
\hline Gaining knowledge and skill & Using the gained knowledge and skill & $\begin{array}{l}\text { Producing new knowledge and } \\
\text { skill from the gained ones }\end{array}$ \\
\hline $\begin{array}{l}\text { [1] Communication skills } \\
\text { [2] Critical thinking skills } \\
\text { [3] Graphical presentation skills } \\
\text { [4] Research skills } \\
\text { [5] Formal composition systems } \\
\text { [6] Design skills } \\
\text { [7] Teamwork skills } \\
\text { [12] Use of precedents } \\
\text { [13] Human behaviours } \\
\text { [14] Cultural diversities } \\
\text { [15] Accessibility } \\
\text { [16] Sustainable design } \\
\text { [17] Ability to prepare a } \\
\text { comprehensive program } \\
\text { [18] Site conditions } \\
\text { [28] The role of client (user) in } \\
\text { architecture }\end{array}$ & $\begin{array}{l}\text { [6] Design skills } \\
\text { [7] Teamwork skills } \\
\text { [8] History of western architecture } \\
\text { [9] History of entire world (excluding western architecture) } \\
\text { [11] Preservation of historical environment and restoration } \\
\text { [14] Cultural diversities } \\
\text { [16] Sustainable design } \\
\text { [17] Ability to prepare a comprehensive program } \\
\text { [19] Structural systems } \\
\text { [20] Environmental systems } \\
\text { [21] Safety } \\
\text { [22] Building envelope systems } \\
\text { [23] Building service systems } \\
\text { [24] Building systems integration } \\
\text { [26] Control of building costs } \\
\text { [27] Technical documentation } \\
\text { [28] The role of client in architecture } \\
\text { [29] Comprehensive design } \\
\text { [30] Architectural practice \& project management } \\
\text { [31] Practice management }\end{array}$ & $\begin{array}{l}\text { [29] Comprehensive design } \\
\text { [30] Architectural practice \& } \\
\text { project management } \\
\text { [31] Practice management } \\
\text { [32] Professional development } \\
\text { [33] Leadership } \\
\text { [34] Legal responsibilities } \\
\text { [35] Ethics and professional } \\
\text { judgment }\end{array}$ \\
\hline
\end{tabular}

- to highlight different approaches on design.

In this paper, as an informal study example two international workshops is discussed to evaluate the contributions of such informal studios on student's individual and collective learning styles, design thinking techniques and practices.

\section{Method}

\subsection{The Scope and Content}

YTU Faculty of Architecture, Department of Architecture with two of European Architectural Schools held the international workshops "Walking Istanbul 1 \& 2" in order to point out the effects of informal environment in design education for gaining, transforming and communicating knowledge.

As Zeisel (1995) described design has three elementary activities; imaging, presenting and testing. During design process within these activities the knowledge that designers used can be specific and/or general. The main framework of the studies is set on two of design activities_imaging and presenting — and also image information because "image information conveys a feeling or a mood of some environment".

In this context the goals of the studies/workshop series are detailed according to the UIA charter and items 5A-5B-5C capabilities in design and representation skills.

The major goal is to understanding different city structures:

- By working on a historical urban context via,

- Design elements; rhythm, colour, material and texture, proportion, module, symmetry, movement and concept of space is the main theme of the studio series.

In Walking Istanbul 1, Rhythm \& Colour and in Walking Istanbul 2, Texture \& Material were studied in the historical peninsula of Istanbul in two old settlements that are next to each other. The second aim is to encourage sketching with freehand drawings so beside verbal presentations especially the observations also wanted to be accompanied by sketch drawings.

According to Pallasmaa (2009), "sketching and drawing are spatial and haptic exercises that fuse the external reality of space and matter... in our time computer has broken sensual and tactile connection between imagina- 
tion and the object of design”. The freehand drawing is the reflection of perception, expression, observation and all these realized in different steps depending on the stimuli in same time.

The study seeks to answer some questions:

1) Where is the motto "learning by doing" in architecture standing? Is it still valid?

2) How do architectural students utilizeeye-mind-hand correlation? (Draw from observation-reflection of perception-expression of the perception)

3) How do architectural students give meaning to what they see? (Visual perception—abstracting reality)

4) What tools do architectural students use for abstracting reality? (Using basic design elements such as point, line, surface and or form in abstracting)

\subsubsection{About the Site}

Students were requested to work on an area of application that will offer a variety of data such as enriched in visual perception, stimulating, focusing. With this prediction a historic district was elected as site.

Two neighbourhoods, facing Golden Horn, Fener and Balat from historical peninsula of Istanbul are chosen as study area to emphasize different city structure. Both neighbourhoods are laying on a sloppy topography. In Fener the organic planning is used where as in Balat the structure of planning is grid system (Figure 1). Other differences in these two neighbourhoods are the inhabitants during the Conquer of İstanbul. Before the Conquer (1453) Greek noble families were settled in Fener region and after the Conquer Jewish people were settled in Balat. Through out history due to political and social changes the inhabitants moved to Greece and Israel. As a result of inner immigration at 1950's rural people (man power) settled in both areas. Nowadays the profile of the tenants is low-in come families. Another significant difference of the neighbourhoods is the architectural formation both in institutional building and houses (Figure 2 and Figure 3).

In Fener houses are 2 - 3 floors masonry mansion detached or separated with gardens. The houses belonging to wealthy Greek families on the Golden Horn shore were blocked with the new seashore road after 1984. Other distinguishing buildings in Fener are Orthodox Church, patriarchate of Istanbul and the Greek Boys School.

In Balat region as a result of more simple life compared to Fener, the plots are narrow and the dimensions of the houses are smaller. There are many synagogues in Balat. The wooden structure is renewed after each fire but finally masonry took place. The most significant building in the area is "Wooden Minerat" mosque and Turkish bath, border of Fener and Balat (Figure 4 and Figure 5).

\subsubsection{People and Duration}

The workshop studies held in 2010-2011 academic year, one in spring (29 April-4 May 2010) and the second one in fall (9-12 November 2010) semester. Both studies lasted for four days including the weekends. There was no set prerequisite for both workshops and the participation numbers of workshops in total were 9 faculty members and 60 students (10 from UPC, 21 from ZHAW and 29 from YTU) from different years.

\subsection{Procedure and Development}

The fundamental principle in the workshop is for students spending almost all possible time in the field rather than spending it in a limited space, classroom. At the beginning of the workshop the classroom was used only for general information and meeting each other. All remaining working, eating, resting and even chatting actualized in the field. The final exhibition was in the university because there were no efficient places in the field for the result products of the workshop.

Introduction meeting, seminar on theme, neighbourhood and Istanbul, site trip and final exhibition are the main steps of the study. Rather than giving a topic to the students for them to research on, lecturers were with the students all through the workshop visiting the neighbourhood. To set sense of place, first the students are let to see and experience life in the area and internalize than read (trace) the physical properties of the area. Another important subject of the workshop is that students used only pen and paper as a tool for expressing themselves. Hand will be using pencil to transmit image formed in the mind and visual image will be reflected on paper.

The roadmap needs to be clarified delicately in such an open-ended study. Lecturers remained in the background and acted as a member of the group. And through all of these studies, the weight of informal environment kept its continuity at each stage. The formal environment, school, has been used only for the preparation and evaluation phases of final exhibition. 


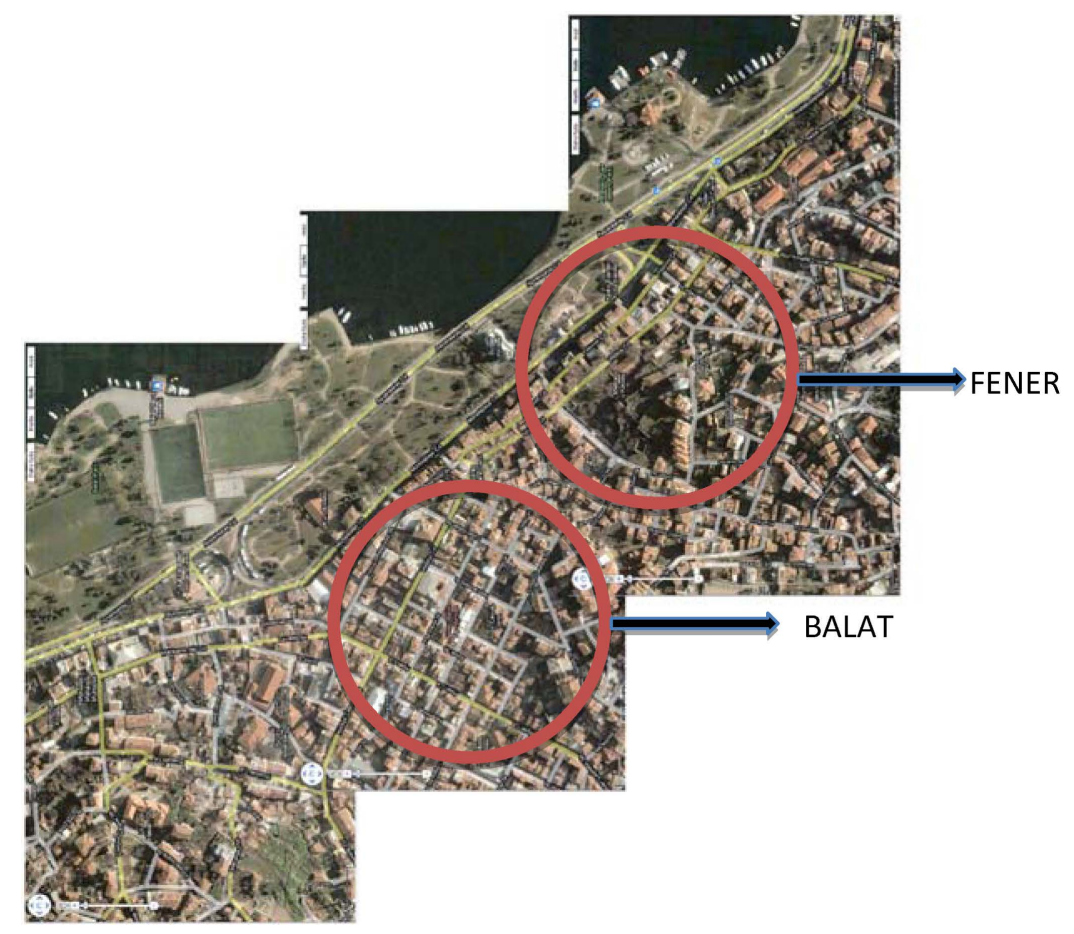

Figure 1. The Google map of the site. (https://maps.google.com)

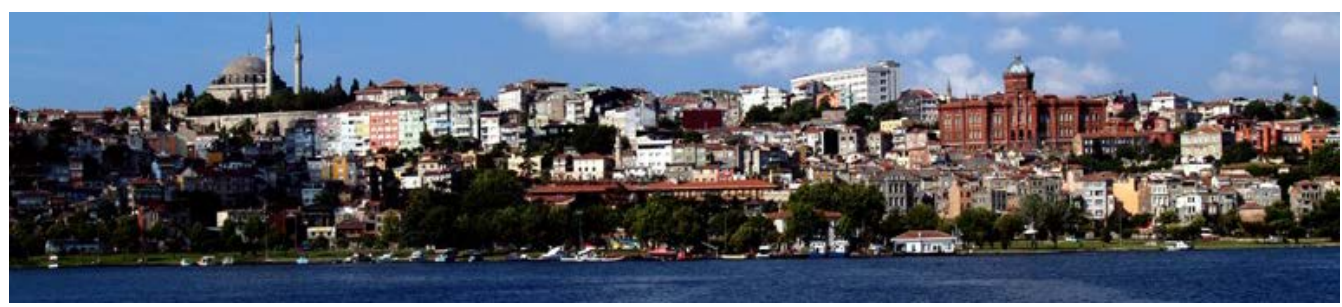

Figure 2. General view of Fener from Golden Horn. (http://www.fatih.bel.tr/bpi.asp?caid=631\&cid=115)

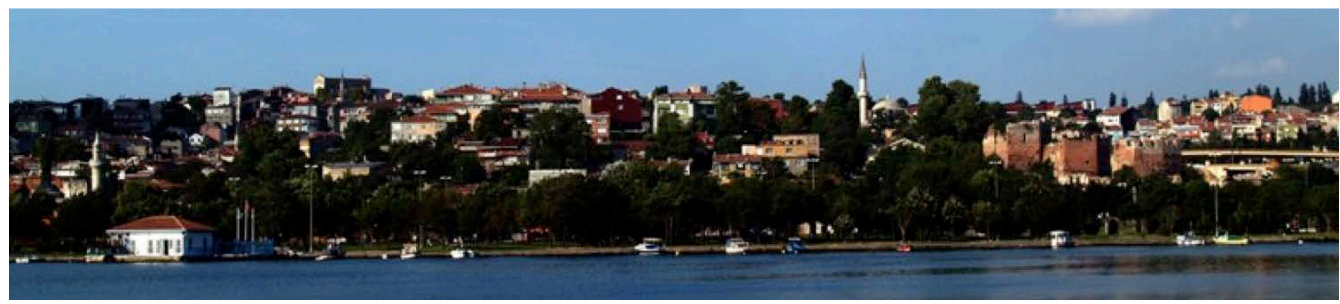

Figure 3. General view of Balat from Golden Horn. (http://www.fatih.bel.tr/bpi.asp?caid=631\&cid=115)

Meetings, communication with locals, lunches and study took place all at the site so that students are conducted in the area to experience a longer period of time, to monitor the behaviours of local people, to perceive the use of space.

One of the most important aims of these workshops was to gather students together from different cultures. For example in the first workshop Spanish students were hosted at Turkish student homesand group activities such as a lunch eaten at the cost of Golden Horn (Figure 6). In the second workshop meeting-group discussion was held at a restorated old house used as a coffee house. Students sitting together on the sidewalk of a street for sketching, or in the afternoon sitting on stools and watching Topkapı Palace while eating fish \& bread were the examples of converging cultures. Students learned not only from the lecturers but also from their peers and shared their experiences. 


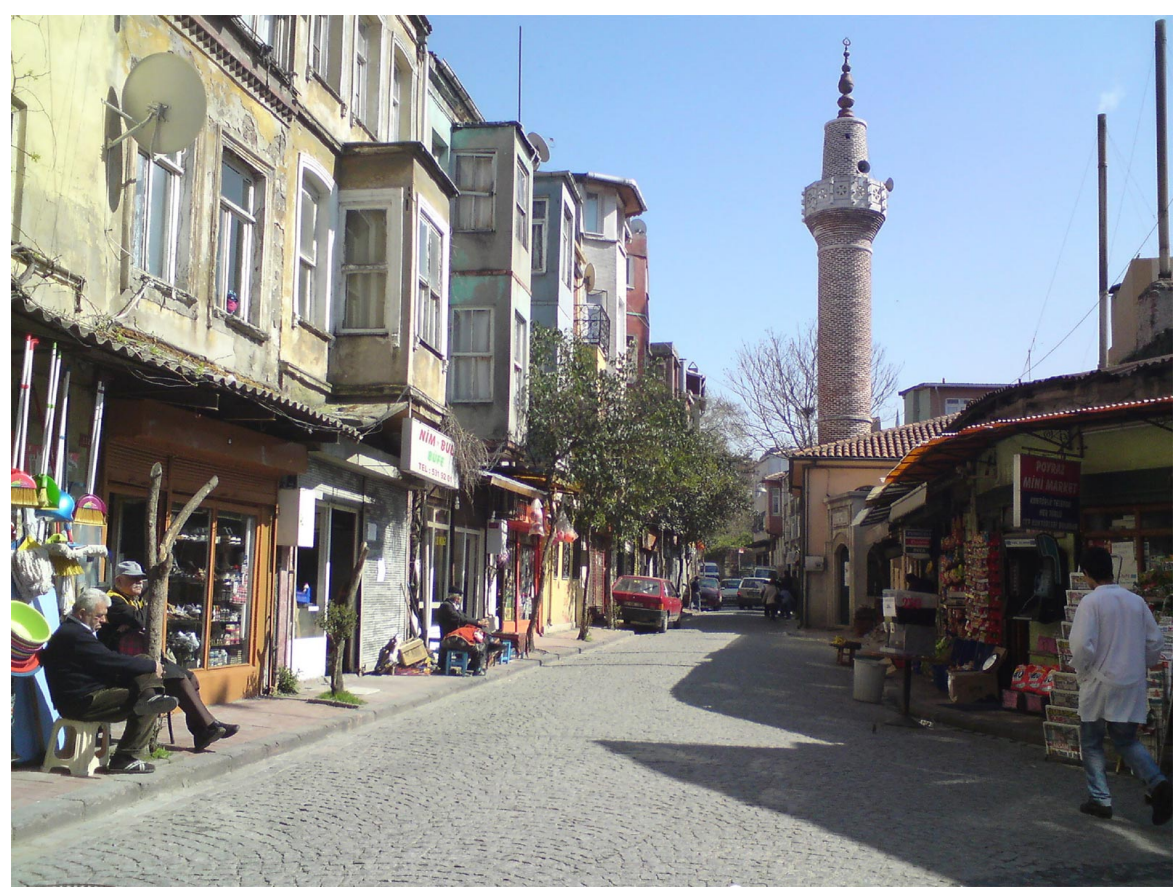

Figure 4. Centre of Balat; the mosque, market place, bath. Photo: Ç. Polatoğlu.
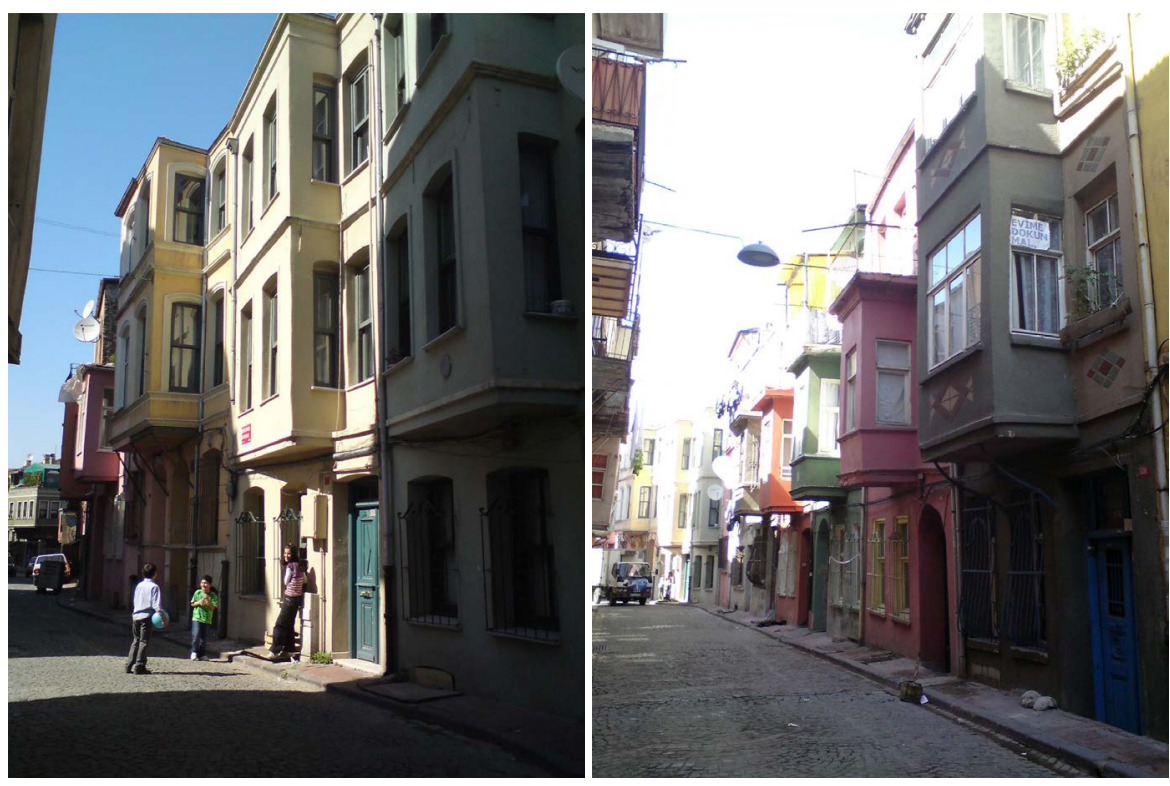

Figure 5. Row houses of Fener. Photo: S. Müjdem Vural.

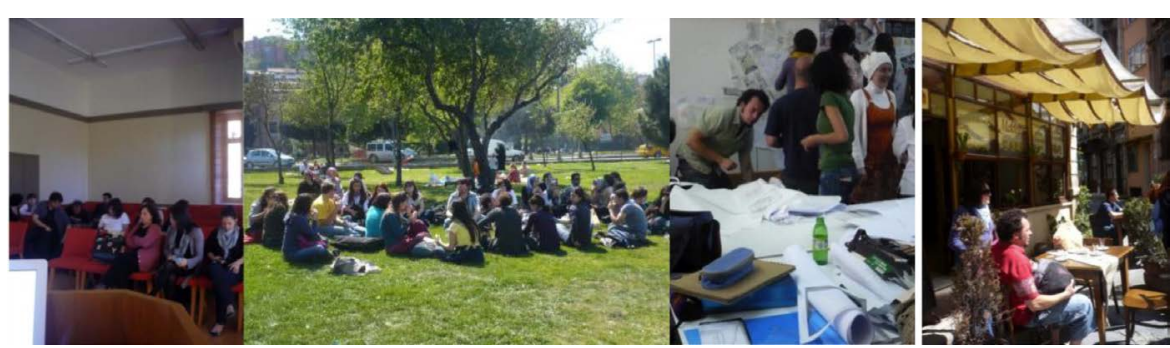

Figure 6. Various social and educational activities (Photos: Ç. Polatoğlu \& S. M. Vural). 
In the context of the chosen themes, students were asked to use free-hand drawings for their examinations but they were free in presentation techniques. In the introduction meeting, rather than a comprehensive course, a short lecture about the theme and the area was given to the students. The goal of this short introduction was to reach the image created by their own research and observations in their minds. For reaching and explaining of this image, it was told that reading through the chosen themes must be done and if needed additional concepts could be used. Just as in the first workshop, along with the theme rhythm, movement and colour elements were given in the presentations.

Field study was planned in three stages. In the first stage all of the participants walked through the area and got the advance information of two neighbourhoods. Second stage was aiming to focus on individual impressions, hence students were asked to present the most effected objects. At the end of this stage all students told their self-experiences in an afternoon meeting where participants got to know each other and verbal communication was developed. Then in the third stage, group formed by 3 - 5 students had a discussion on the collective memory. The formation of the groups was balanced; trying to keep equal number of students from each school. In this last stage collaboration of cultures within social interaction extended to create an architectural platform which different ideas shared.

\section{Evaluation; Discussion on the Results}

\subsection{The Classification of the Drawings; Impressions and Conceptualization}

The sketches of students from each workshop were collected and analysed in the final jury.

The jury evaluated/discussed the sketches according some criteria, which formed in scope of the questions, set in the beginning.

- From observation to drawing,

- Abstraction, conceptualization,

- Emphasising tools of design elements.

Figures 7-15 cover some free hand drawings of the students to emphasize how they,

- Perceive the given design elements,

- The presentation techniques they choose,

- The level of conceptualization.

As a reflection of the eye-mind-hand relation the conceptualization of the site was acquired in different levels according to the students perception and impressions about the site. The drawings of the local students were much more reflection of an overall perception and the guest students were keen on details.

This result verifies the active role of experiencing a place for the first time or being familiar to a certain place in perception. This aspect in international workshops (where the students have the same education system but have different cultural backgrounds) widens point of view and underlines importance of lateral thinking in design.

\subsection{Exhibitions}

Two exhibitions were the end products of both workshops. However it should be noted here that preparation of the exhibition was not just hanging things on display surfaces in the classical sense but weaving a mental map of the chosen theme and the work area, creating collective memory with personal meaning (Figure 16). Preparation of the exhibition was an all-daylong procedure. Evaluation of the workshop conducted jointly by both lecturers and students. Each student gave his/her approach by telling the best-described thing (the physical part of a building or a moment of the local life) interesting for them in the context of the theme.

\subsection{Assessment; the Success Degree of the Studio}

After the joint evaluations of the instructors, the students were asked to answer a self-assessment questionnaire about the studio (Table 2).

Additional comments, which are taken directly from the questionnaire, are as:

- Gained new point of views by following the work of people specialized in different disciplines,

- Spending a joint production process with architects and architectural students from abroad will help in myself improvement, 

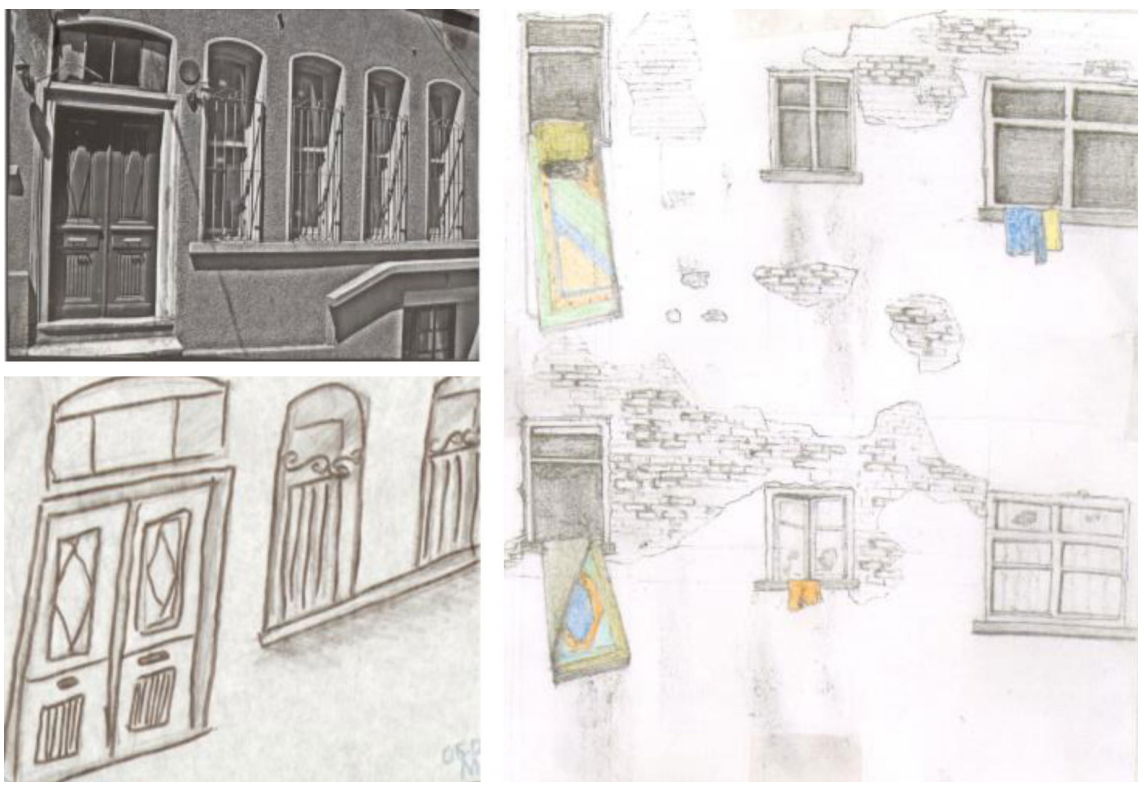

Figure 7. From observation to drawing: Windows of Fener-Balat; single building elements, the primary element of rhythm in facades.

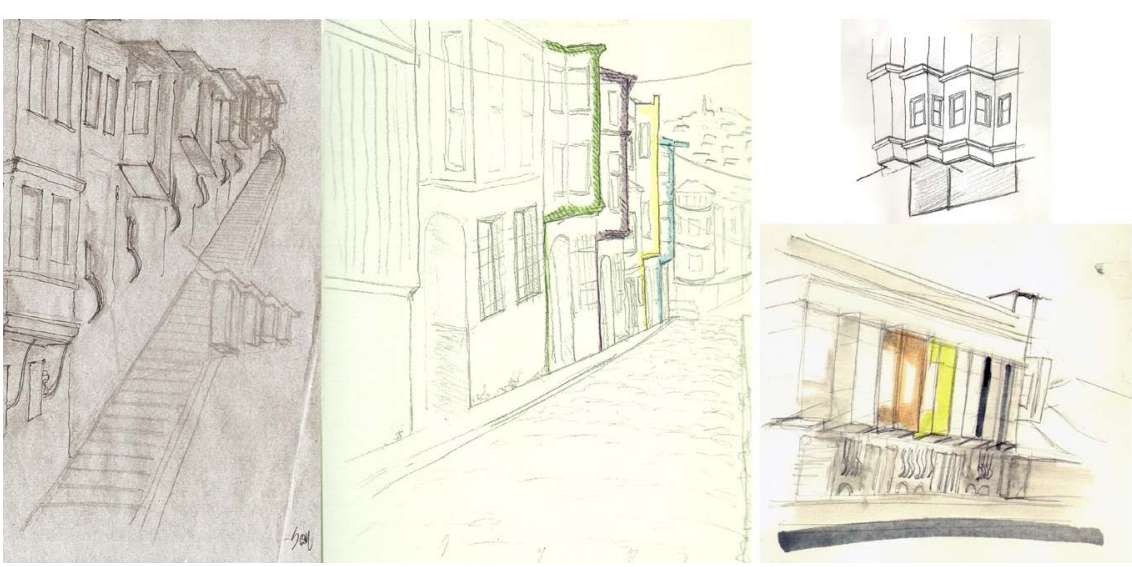

Figure 8. Göz From observation to drawing: Bay windows; major elements reflecting the rhythm both in houses and the streetscape.

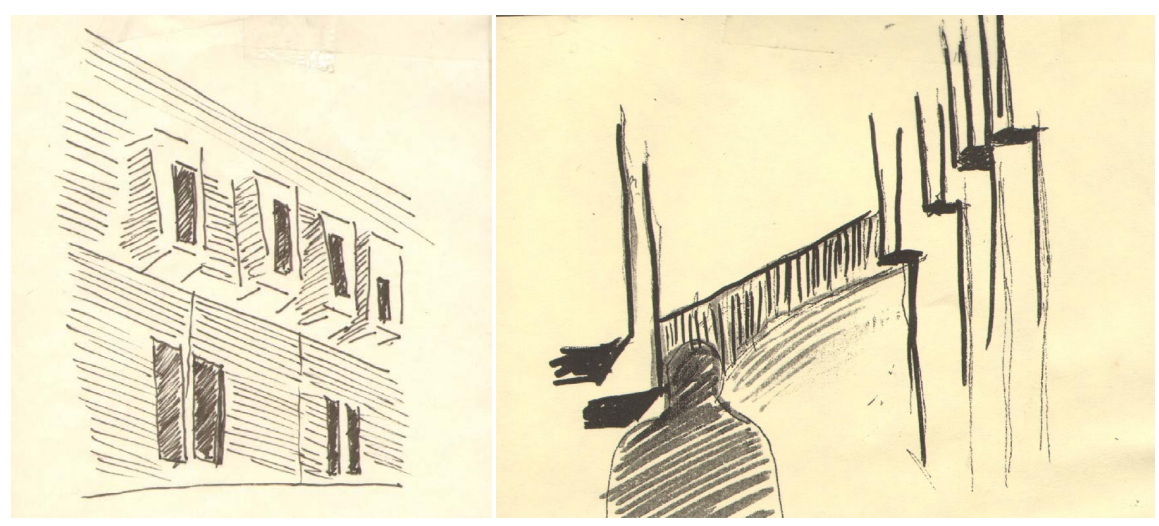

Figure 9. Conceptualization: students used basic design element "the line" to reflect their perception of bay windows even horizontal or vertical positioned. The idea was to show the movement that makes rhythm effective. 

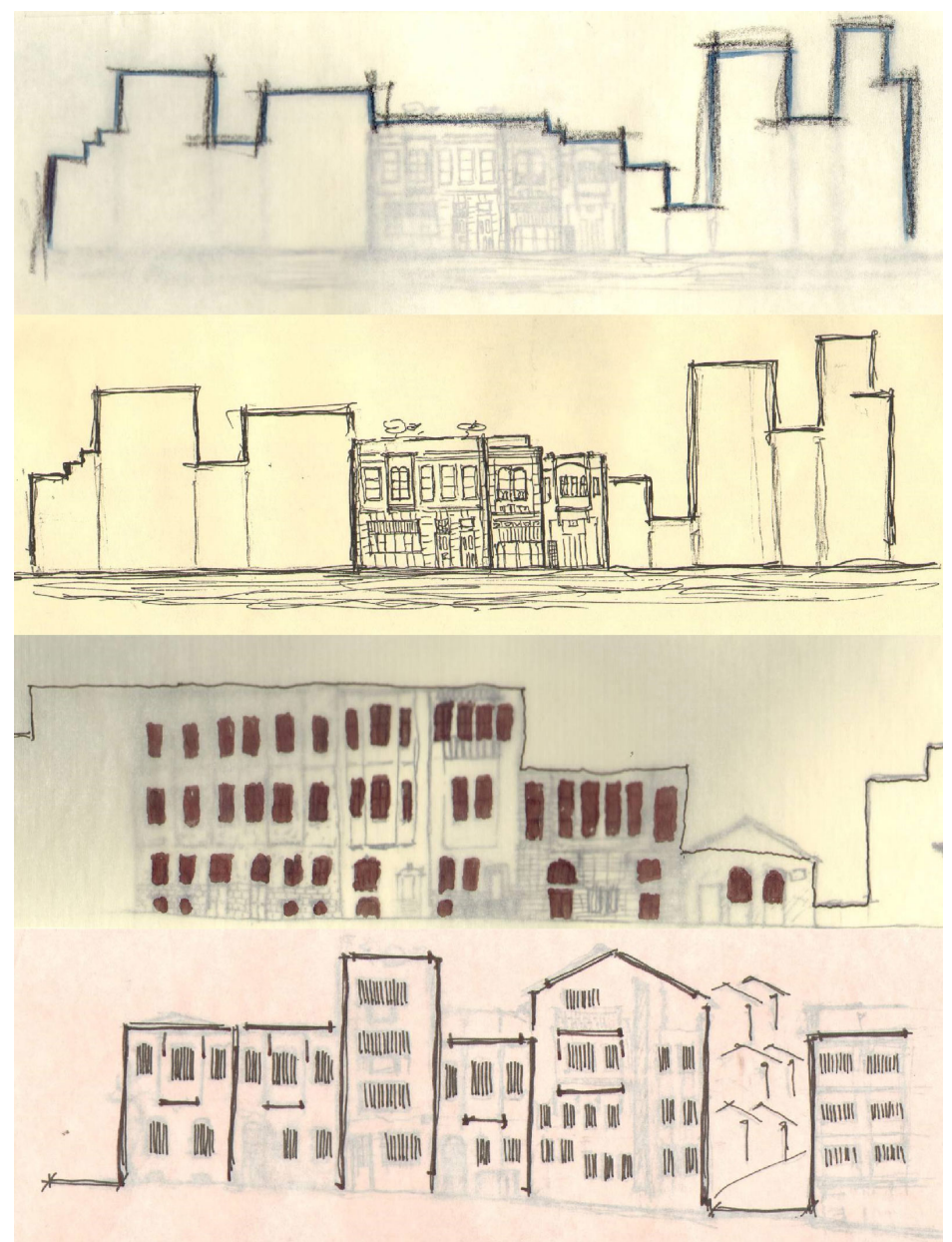

Figure 10. Analysing and Conceptualizing: The streetscape; the linear conceptualization is made to show the rhythm elements, windows, bay windows, module and intersection with skyline.

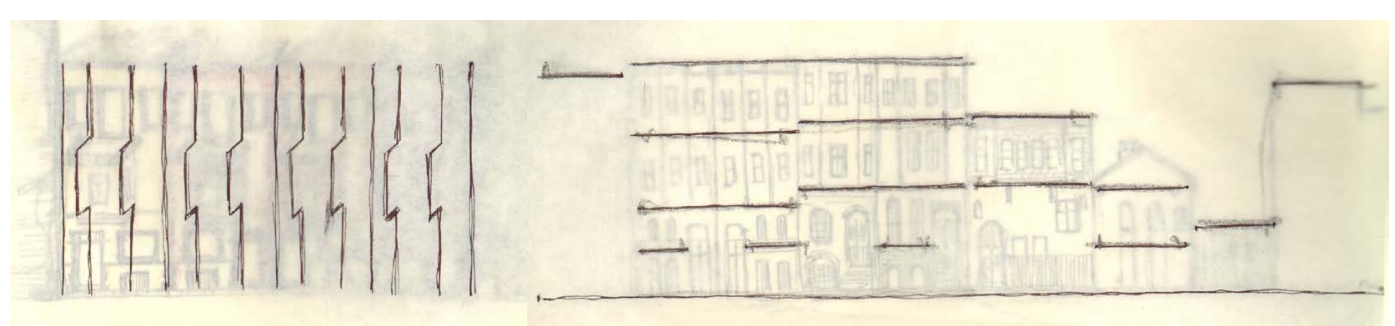

Figure 11. Conceptualizing the streetscape; vertical and horizontal lines used to strength the idea of rhythm.

- Contributed to improving social life and myself,

- I found the workshop very useful and I learned different methods of architecture, had friends from different cultures. It was an experience where I had fun and learned as the same time. As a result I cannot stop myself talking about the workshop all the time. I am grateful to the lectures that organize such kind of events.

\section{Conclusions}

Yildiz Technical University (YTU), Faculty of Architecture, Department of Architecture with two of European Architecture Schools (Catalunya Polytechnic University, UPC and Zurich University of Applied Sciences, ZWAH) held the international workshops (design studios) of "Walking Istanbul 1; Rhythm in Fener-Balat" 


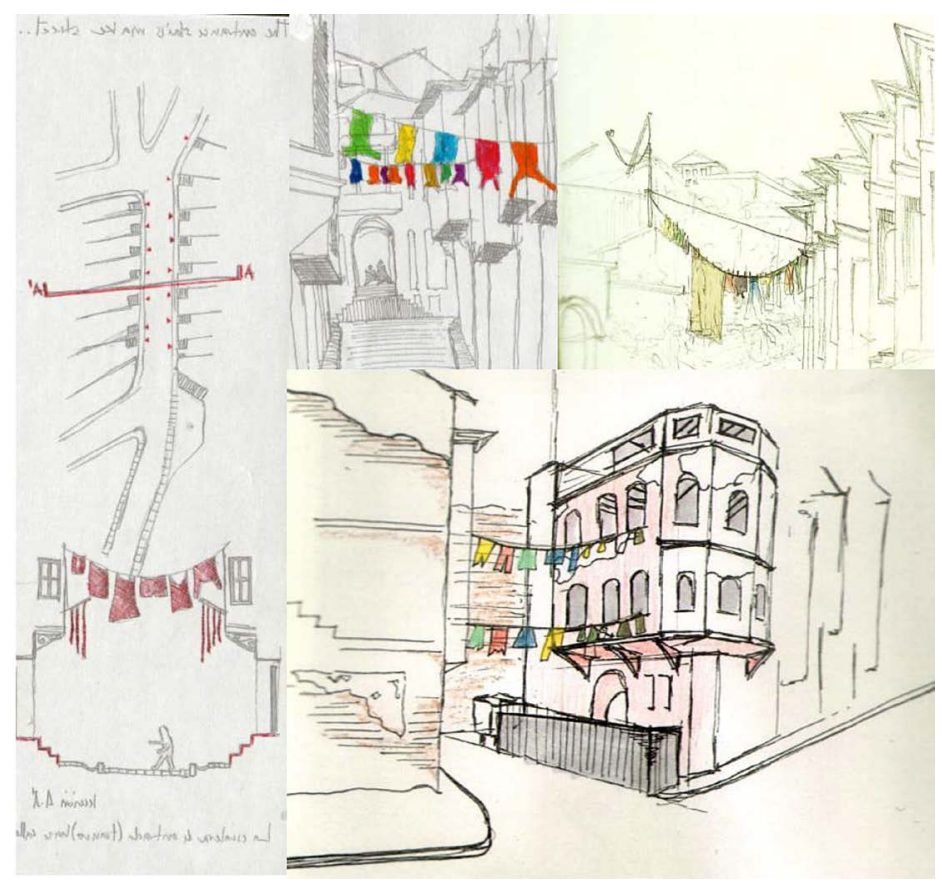

Figure 12. Rhythm in daily life; besides building elements some physical elements reflecting the daily habits such as hang-clothes line recognized by students. Most of them perceived the colourful movement of the clothes hanging over the streets.

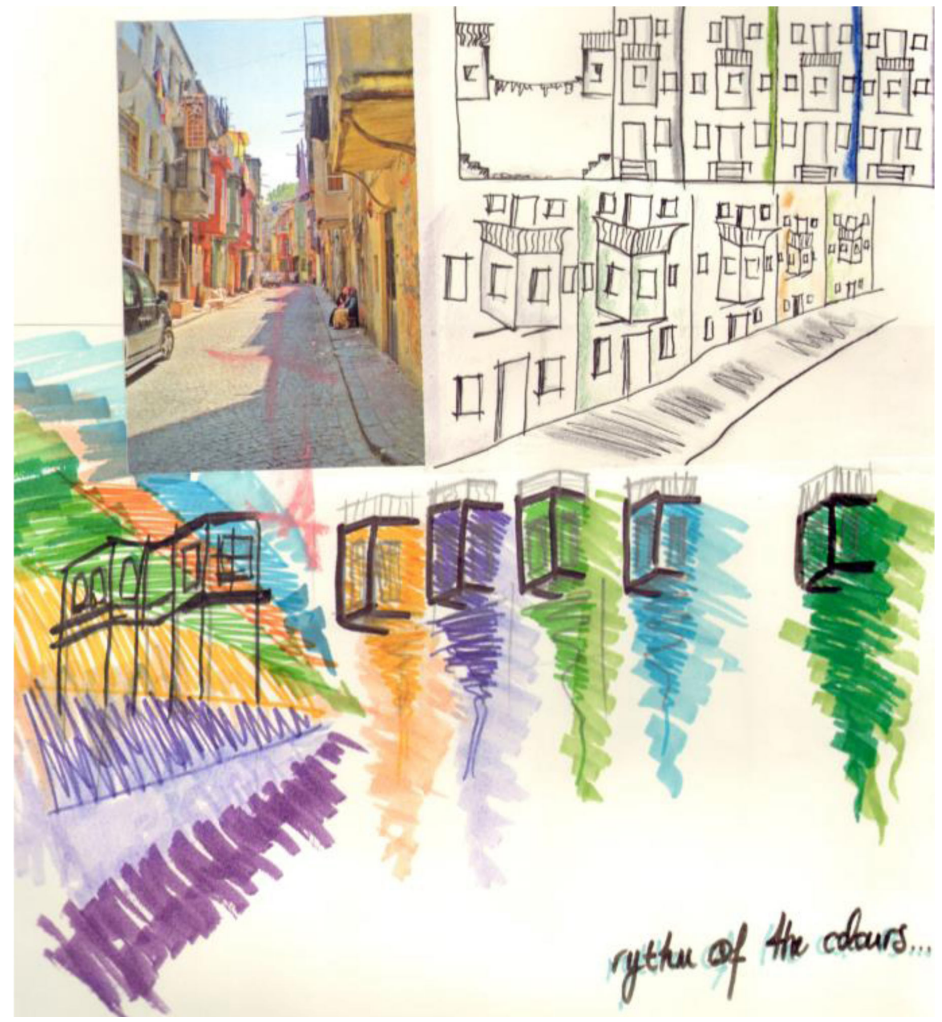

Figure 13. An overall perception; observation and conceptualization with lines and colour: Atypical presentation, the photograph, the street, the elements of rhythm and colour. 


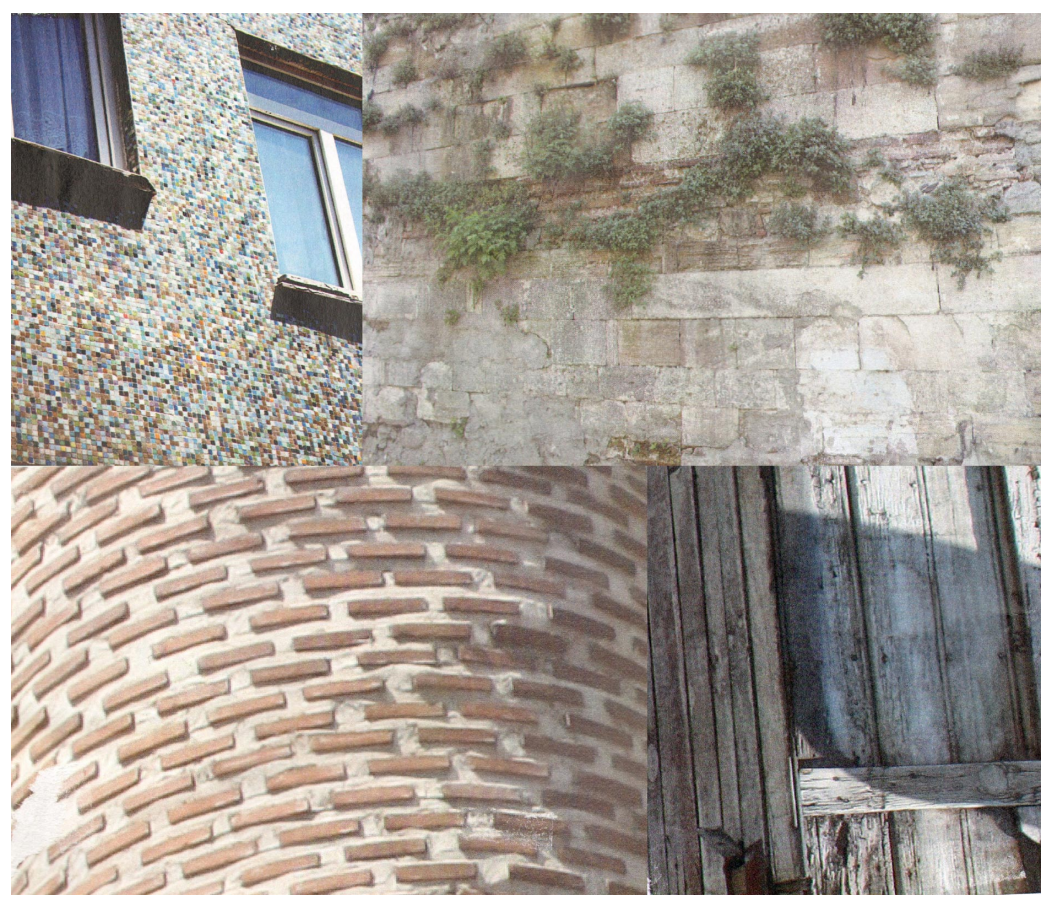

Figure 14. Various materials and textures in Fener-Balat.

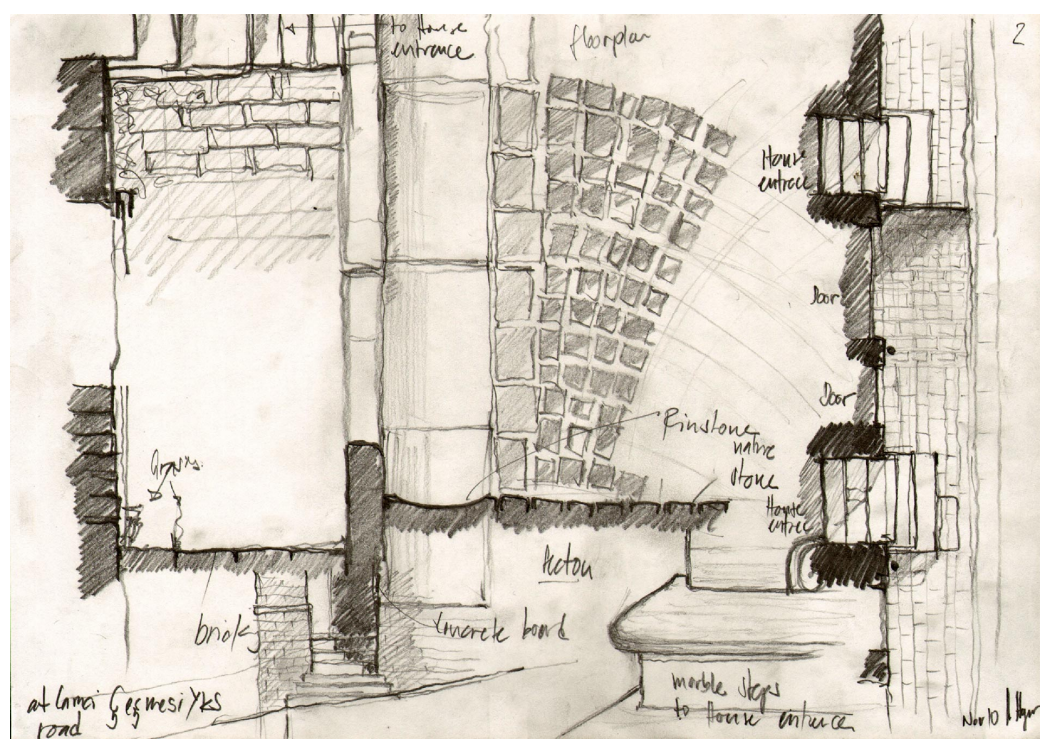

Figure 15. A very detailed vision on material and texture; the pavement pattern.

and "Walking Istanbul 2; Texture \& Material in Fener-Balat" to set awareness of different city structures. The results of these studies assure a supportive environment for gaining, transforming and communicating knowledge in architectural design education. The study has some results for the aimed questions:

1) Beside formal education especially in architectural education the informal studies are supportive activities in terms of improving students' individual and collective learning techniques and also achieving the design thinking techniques and practices.

2) Students used major basic design element "line" for transferring their perception of the real world to paper. This line is not a physical thing that has been drawn but it is a line used for giving a meaning and abstracting. Secondly students used "color" as an element for symbolizing linear abstraction. Contemporaneously "texture" expressions have been the primary element for describing different visual effects of material. 


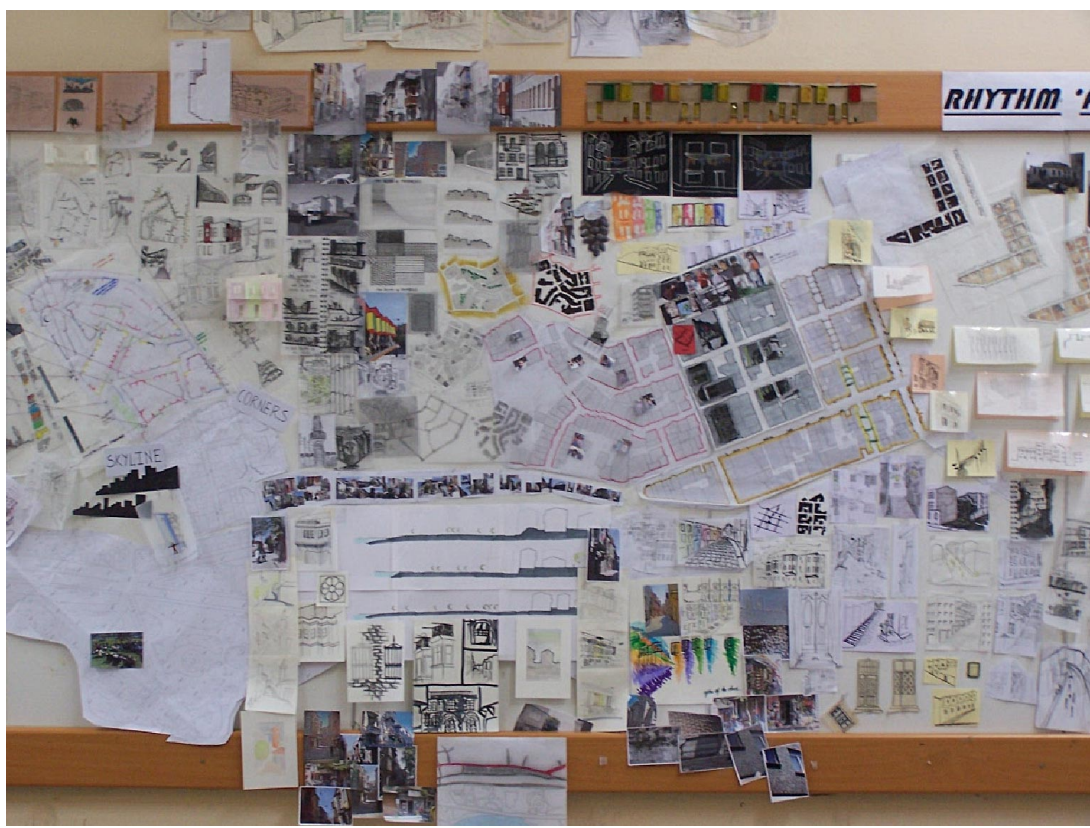

Figure 16. Exhibition display of Rhythm. Photo: S. MüjdemVural.

Table 2. Evaluation chart of the knowledge, skill and experiences gained during the studies.

\begin{tabular}{lccc}
\multicolumn{1}{c}{ Acquisition } & Less & Medium & Much \\
\hline Culture & & 10 & 8 \\
Cultural development & 4 & 14 \\
Social development & 2 & 4 & 14 \\
Design development & & 3 & 10 \\
Creative thinking & 2 & 3 & 12 \\
Problem solving skill & 2 & 3 & 10 \\
Presentation-representation techniques & & 5 & 11 \\
Development of communication skills (verbal) & 1 & 3 & 13 \\
Development of analysing techniques & 2 & 4 & 10 \\
Development of synthesis & 2 & 6 & 7 \\
Development of design evaluation techniques & 1 & 5 & 11 \\
Professional development & & & \\
\hline
\end{tabular}

3) In the study, students were asked to do freehand drawing. In this regard students of different education levels or different manual skills are aligned from simplest to most detailed drawings of explanation that give hint to students' future professional stance.

4) It is evident that all students participating in two workshops highlighted the importance of cultural and social development and stated the self-development through all stages of design.

From this point of view integrated studios-collaboration of formal and informal organizations - in architectural design education will provide a multi-dimensional and dynamic construction by creating a participatory and interactive study environment with the help of increasing the communication between the candidate, lecturer, other actors of profession and other disciplines.

The forthcoming Walking İstanbul series will handle cover/feature the concepts of proportion-module-symmetry-movement and will last with the concept of space to gather all the concepts together with the participation of all schools. The results of these studios will be shared also in academia. 


\section{Acknowledgements}

We would like to thank to Rectorate of Yildiz Technical University, International Urban Studies Centre of YTU and participating schools.

\section{References}

Pallasmaa, J. (2009). Lecture 26 May 2009, Manuscript, XXXIII. MOBBİG Meeting Erciyes University Kayseri-Turkey.

Polatoğlu, Ç., \& Canbay Türkyılmaz, Ç. (2009). YTU Architectural Design Studio 3: Experiences of Second Year. Proceedings of Architectural Design and Construction Education Experimentation towards Integration, ENSHA-EAAE Conference, Architectural Design Teachers' and Construction Teachers' Networks, Genoa University Architectural Faculty, Genoa, 369-378.

Polatoğlu, Ç. (2011). Tasarım Eğitiminde Enformel Etkinliklerin Önemi; YTÜ Mimarlık Bölümü Çalışmaları. XXXIII. MOBBİG-Erciyes Üniversitesi Mimarlık Bölümü, Kayseri.

Ünver, R., Polatoğlu, Ç., \& Vural, S. M. (2013). Architectural Education in The Globalizing World; The Experience in YTU. In: B. Bolak Hisarligil, S. Lökçe, \& O. Turan, MIMED Forum IV: Flexibility in Architectural Education, Cambridge Scholars Publishing (CSP), 110-133.

Zeisel, J. (1995). Inquiry by Design: Tools for Environment-Behavior Research. Cambridge: Cambridge University Press. http://www.uia-architectes.org/image/PDF/CHARTES/CHART_ANG.pdf

http://www.fatih.bel.tr/bpi.asp?caid=631\&cid=115 